\title{
Narcoleptic-like Episodes in a Patient Receiving Pegylated Interferon-alpha 2b: A Case Report and Review of Literature
}

\author{
BENJAMIN O. LAWSON ${ }^{1}$ and HUNG T. KHONG ${ }^{2}$ \\ ${ }^{1}$ Honor Health Internal Medicine, Scottsdale Thompson Peak Medical Center, Scottsdale, AZ, U.S.A; \\ ${ }^{2}$ Department of Oncology, Huntsman Cancer Institute, University of Utah, Salt Lake City, UT, U.S.A.
}

\begin{abstract}
A 26-year-old male developed narcoleptic-like episodes while on pegylated interferon-alpha $2 b$ (peg-IFN$\alpha 2 b)$ therapy for stage IIIB melanoma. Once peg-IFN- $\alpha 2 b$ was discontinued, the narcoleptic-like episodes eradicated. A case report and review of the literature are presented in this article.
\end{abstract}

\section{Case Report}

A 26-year-old man was in his usual state of health until July 2012, when his girlfriend accidently nicked his scalp while cutting his hair. This region of the scalp began to bleed, did not heal, and minimal trauma resulted in recurrent bleeding. This eventually led to a dermatology evaluation. Dermatology discovered a $16 \times 14 \mathrm{~mm}$ erythematous inflamed nodule with "black specks" and an adjacent plaque macule. This discovery resulted in an excisional biopsy in which pathology noted a $1.2 \times 0.9 \mathrm{~cm}$ ulcerated lesion, superficial spreading melanoma, Breslow depth $3.8 \mathrm{~mm}$, Clark level IV with 12 mitoses per $\mathrm{mm}^{2}$. No regression was identified, no satellitosis or angiolymphatic spread was noted.

From a sentinel lymphadenectomy in October 2012, pathology reported positive residual malignant melanoma, Breslow depth $3.75 \mathrm{~mm}$ with 1 of 4 lymph nodes positive for a $1.2 \mathrm{~cm}$ deposit of atypical melanocytes within lymph node parenchyma. However, no evidence of extracapsular lymph node was identified. Staging workup was negative for distant metastasis. The final pathologic stage is pT3bpN1aM0, stage IIIB.

The patient's past medical history was unremarkable except for the occasional psychosocial stressor induced

Correspondence to: Associate Professor Hung T. Khong, MD, Huntsman Cancer Institute, 2000 Circle of Hope, Salt Lake City, UT 84112, U.S.A. Tel: +1 8012134260, e-mail: hung.khong@ hci.utah.edu

Key Words: Pegylated IFN- $\alpha 2 \mathrm{~b}$, melanoma, narcolepsy, loss of consciousness, syncope. depression. The patient denied any family history of melanoma. His social history was that of rare use of alcohol, currently was working 2 jobs; bowling alley attendant and welder. He obtained an associate's degree in welding and denied any exposure to radiation in the past. The patient was not on any medications and denied any known drug allergies.

In April 2013, his 12 point review of systems was negative and he was started on the following adjuvant regimen of subcutaneous peg-IFN- $\alpha 2 \mathrm{~b} 6 \mu \mathrm{g} / \mathrm{kg}(686 \mu \mathrm{g})$ weekly for 8 weeks, followed by $3 \mu \mathrm{g} / \mathrm{kg}$ (342 $\mu \mathrm{g}$ ) weekly for up to 5 years. Current literature side effects were discussed in detail and fully understood by the patient.

When he returned for follow-up in May 2013 post 4 injections of the peg-IFN- $\alpha 2 b$, he reported muscle aches 34 days after injection, which were not incapacitating and controlled with ibuprofen or acetaminophen; he also reported and two peculiar episodes. The first episode occurred on a Monday night when he was sitting in his truck, about to call his wife and suddenly passed out and awoke in the morning. The second episode occurred two days later while he was sitting in his backyard. Suddenly, passed out and awoke in the morning. There were no warnings, lightheadedness, vision changes, headache, weakness or tingling, or loss of bladder and/or bowel control.

On Physical exam, he had a temperature of $36.6^{\circ} \mathrm{C}$, pulse $72 \mathrm{bpm}$, respirations of 16 , pulse ox $96 \%$ on room air, blood pressure 115/72. No central nervous system, cardiovascular, respiratory, gastrointestinal, musculoskeletal, or psychiatric defects noted on exam. Complete blood count was within reference range except for platelets of 144,000 (177-406), granulocytes of $41.2 \%$ (44-76\%), lymphocytes of $47.5 \%$ (25$30 \%$ ), monocytes of $10.2 \%$ (0\%-9\%). Comprehensive metabolic panel was within reference range except for a chloride of $112 \mathrm{mEq}$ (100-106mEq). Lactate dehydrogenase was elevated at $292 \mathrm{IU} / \mathrm{L}$.

Magnetic resonance imaging (MRI) of the brain with and without contrast showed no evidence of intracranial metastatic disease. Subsequent electrocardiogram (ECG), 
complete blood count, comprehensive metabolic panel, computed tomography scan were performed and all unremarkable.

Since what the patient described seemed to be narcolepsylike episodes, we tested for human leukocyte antigen (HLA)DQB1*06:02, the HLA antigen commonly associated with narcolepsy, which was negative.

Due to these two episodes, peg-IFN- $\alpha 2 \mathrm{~b}$ was permanently discontinued after 4 injections, and the patient was referred to a neurologist for further investigation. Due to financial concern, the patient did not follow up with Neurology. When the patient followed up in June 2013, no other episodes were experienced.

\section{Discussion}

These two episodes could be explained as syncope which is described as an abrupt and transient loss of consciousness associated with the absence of postural tone, by complete and usually rapid spontaneous recovery. It is also described as fainting or passing out (1). Syncope is typically caused by cardiac arrhythmias, structural cardiac or cardiopulmonary disease in terms of blood flow obstruction, vasovagal (most common cause (2), orthostatic hypotension, or cerebrovascular disease.

Prodromal symptoms, complaints during the spell, and symptoms after the episode as well as loss of consciousness after exercise, micturition, defecation, and stressful events is generally due to syncope (3). Secondly, symptoms such as sweating and nausea during the episode are associated with syncope (3). Lastly, a long duration of loss of consciousness (>5 minutes), disorientation after the event, and slowness of return to consciousness suggest a seizure (4). Since the duration of these episodes occurred through the night, syncope is less likely.

Physical exam findings that can aid in the identification of syncope include orthostatic hypotension, irregular heart rate, murmurs, unilateral neurological abnormalities reflecting a cerebral vascular accident, and positive stool guaiac (5). Electrocardiogram can portray the any of the following: bifascicular block, intraventricular conduction abnormalities, Mobitz I second degree atrioventricular (AV) block, sinus bradycardia, pre-excited QRS complexes (Wolff-ParkinsonWhite syndrome), long or short QT intervals, right bundle branch block with ST elevation in leads V1-V3, negative T waves in right precordial leads, epsilon waves and ventricular late potentials, or Q waves (6). Due the absence of physical exam findings as well as an unremarkable sub sequential ECG, once again syncope is unlikely.

Due to the financial burden of the patient, Neurology or Cardiology was not followed up with and therefore other work ups such as tilt test, echocardiogram or 24 hour Holter monitoring were unobtainable.
The second explanation for these episodes could be a complex partial seizure or generalized seizure. By definition seizure is the manifestation of a paroxysmal discharge of abnormal rhythms in some part of the brain (7). Seizures are usually preceded by precipitants or triggers such as, strong emotions, intense exercise, loud music, and flashing lights $(8,9)$. Seizures are usually followed by a postictal state, which manifests as confusion and suppressed alertness, or postictal paresis, which manifests as a transient neurological deficit.

Laboratory studies that aid in the diagnosis of seizures include a metabolic panel especially testing for electrolyte, renal, or liver abnormalities (10). Other exams that were unfortunately not obtained in the above patient due to financial burdens include electroencephalogram, serum prolactin, lumbar puncture, or MRI. Even though MRI of the brain was performed in the patient, it was read as unremarkable. Even though the duration of these described episodes meets the criteria of a seizure, it is highly unlikely it was seizure due to the lack of other findings.

The diagnosis of drug-induced narcolepsy is one of exclusion. The clinical picture, electrocardiogram laboratory values are all that of normal. Common symptoms and findings include intermittent excessive daytime sleepiness, cataplexy or emotionally triggered transient muscle weakness, sleep paralysis and hypnagogue/hypopompic hallucinations (11). The polysomnography reveal spontaneous awakenings, mild reduced sleep efficiency, and may show rapid-eyemovement (REM) sleep within 15 minutes of the onset of sleep (12). Evidence suggests a strong association with HLA DQB1*06:02 with a predisposition of narcolepsy (13). Cerebrospinal fluidtesting to measure hypocretin-1/orexin A levels, which would be low in narcolepsy (13), as well as serum levels of Immunoglobulin (Ig)G, IgM, IgA autoantibodies reacting with hypocretin-1 peptide can be tested using enzyme-linked immunosorbent assay (ELISA) and then confirmed with Western blot (14). Levels of hypocretin-1 total IgG autoantibodies are higher in narcolepsy-cateplexy patients (14).

Some background information includes hypocretins are exclusively synthesized in the lateral hypothalamus and are derived from a single protein precursor name preprohypocretin (13). Hypocretin-secreting neurons project from the lateral hypothalamus throughout the central nervous system (CNS) to neurons involved in the regulation of feeding, sleep-wakefulness, neuroendocrine homeostasis, and autonomic regulation (13).

To begin, there has been an increased onset of narcolepsy following infections primarily with upper airway infections from Streptococcus pyogenes and the influenze A virus (13, 15-17). The development of narcolepsy in association with upper airway infections could result from various processes, including molecular mimicry and bystander activation (13). 
Molecular mimicry would involve processing and presenting bacterial and viral peptides in the context of HLA DQB $1 * 06: 02$, which would activate a population of crossreactive $\mathrm{T}$ cells present in predisposed individuals (13). Bystander activation from the generalized proinflammatory environment associated with infections could facilitate the destruction of hypocretin-secreting neurons (13). Streptococcal infections can induce the production of interleukin (IL)-17 by T cells, which has shown to facilitate permeability of the blood-brain barrier potentially exposing hypocretin-secreting neurons to the immune system (13). This would result in the recent "immune privileged" hypocretinsecreting neurons to the immune system. As the $\mathrm{T}$ cells recognize this area as foreign they stimulate the $\mathrm{B}$ cells to produce antibodies leading the destruction (14) of sleepwakefulness regulation of the hypocretin-secreting neurons.

Recent studies have indicated that pandemrix, an AS03 (squalene, alpha-tocopherol) $\mathrm{H} 1 \mathrm{~N} 1$ vaccine developed in response to the $2009 \mathrm{H} 1 \mathrm{~N} 1$ influenze pandemic, likely contributed to the spike of narcoleptic onset seen among children and young adults in Finland (13). The question is when the immune system is introduced with the adjuvant H1N1 vaccine, does this stimulate $T$ cells to produce autoantibodies, thus increasing IL-17, allowing more T cells to permeate the blood brain barrier and self-attacking the hyopcretin-secreting neurons resulting in narcoleptic-like episodes?

Interferons induce synthesis of hundreds of different proteins by activating the Janus kinase-signal transducers and activators of transcription (JAK-STAT) pathway, which is a major signaling system that cells use to transmit extracellular information from many cytokines and growth factors to the nucleus $(18,19)$. Recombinant IL-2 was shown to have potent, dose-dependent immunomodulatory and antitumor activity in a number of murine tumor models by over activating $\mathrm{T}$ cells (20). Also, IFN $\alpha / \beta$ enable $\mathrm{B}$ cells to undergo isotype switching and differentiation into plasma cells through the activation of dendritic cells (21). Dendritic cells are central to $\mathrm{T}$ lymphocyte activation and differentiation into type-1 T-helper, type-2 T-helper and cytotoxic T lymphocyte effectors (21).

IFN- $\alpha 2 b$ and peg-IFN- $\alpha 2 b$ are approved options for adjuvant therapy of stage III melanoma (22). Due to the autoimmune basis of narcolepsy and the ability for IFN- $\alpha 2 b$ to stimulate the immune system, and due to the fact that the patient was HLA-DQB1*06:02 negative, it is possible that his narcolepsy-like episodes were more likely associated with IFN therapy than genetic predisposition.

\section{References}

1 Shukla G and Zimetbaum P: Syncope. Circ 113(16): 715-717, 2006.
2 Soteriades E, Evans J, Larson M, Chen M, Chen L, Benjamin E and Levy D: Incidence and prognosis of syncope. N Engl J Med 347(12): 878-885, 2002.

3 Kapoor W: Current Evaluation and Management of Syncope. Circ 106(13): 1606-1609, 2002.

4 Eagle $\mathrm{K}$ and Black $\mathrm{H}$ : The impact of diagnostic tests in evaluating patients with syncope. Yale J Biol Med 56(1): 1-8, 1983.

5 Linzer M, Yang E, Estes N, Wang P, Vorperian V and Kapoor W: CLINICAL GUIDELINE: Diagnosing Syncope: Part 2: Unexplained Syncope Ann Intern Med 127(1): 76-86, 1997

6 Moya A, Sutton R, Ammirati F, Blanc JJ, Brignole M, Dahm JB, Deharo JC, Gajek J, Gjesdal K, Krahn A and Massin M: Guidelines for the diagnosis and management of syncope (version 2009). Eur Heart J 30(21): 2631-71, 2009.

7 Bergfeldt L: Differential Diagnosis of Cardiogenic syncope and Seizure Disorders. Heart 89(3): 353-358, 2003.

8 Fisher R, Harding G, Erba G, Barkley G and Wilkins A: Photicand pattern-induced seizures; a review for the epilepsy foundation of America Working Group. Epilepsia 46(9): 14261441,2005

9 Pittau F, Tinuper P, Bisulli F, Naldi I, Cortelli P, Bisulli A, Stipa C, Cevolani D, Agati R, Leonardi M, and Baruzzi A: Videopolygraphic and functional MRI study of musicogenic epilepsy. A case report and literature review. Epilepsy Behav 13(4): 685-692, 2008.

10 Krumholz A, Wiebe S, Gronseth G, Shinnar S, Levisohn P, Ting T, Hopp J, Shafer P, Morris H, Seiden Land Barkley G: Practice Parameter: Evaluating an apparent unprovoked first seizure in adults (an evidence based review): report of the quality Standards Subcommittee of the American Academy of Neurology and the American Epilepsy Society. Neurology 69(21): 1996-2007, 2007

11 Wieczorek S, Dahmen N, Kasten M, Epplen J and Gencik M: A rare form of narcolepsy (HLA-dr2) shows possible association with (functionally relevant) alpha interferon gene polymorphisms. Psyc Gen 14(1): 47-51, 2004.

12 Andlauer O, Moore H, Jouhier L, Drake C, Peppard PE, Han F, Hong SC, Poli F, Plazzi G, O'Hara R and Haffen E: Nocturnal rapid eye movement sleep latency for identifying patients with narcolepsy/hypocretin deficiency. JAMA Neurol 70(7): 891-902, 2013.

13 Mahlios J, De la Herran-Arita AK and Mignot E: The autoimmune basis of narcolepsy. Current opinion in Neurobiology 23(5): 767-773, 2013.

14 Deloumeau A, Bayard S, Coquerel Q, Déchelotte P, Bole-Feysot C, Carlander B, De Cock V, Fetissov S and Dauvilliers Y: Increased immune complexes of hypocretin autoantibodies in narcolepsy. PLOS One 5(10): 13320, 2010.

15 Koepsell T, Longstreth W and Ton T: Medical exposure in youth and the frequency of narcolepsy with cataplexy; a population based case-control study in genetically predisposed people. $\mathrm{J}$ Sleep Res 19(1 Pt 1): 80-86, 2010.

16 Aran A, Lin L, Nevsimalova S, Plazzi G, Hong SC, Weiner K, Zeitzer J and Mignot E: Elevated anti-streptococcal antibodies in patients with recent narcolepsy onset. Sleep 32(8): 979-983, 2009.

17 Han F, Lin L, Warby S., Faraco J, Li J, Dong S, An P, Zhao L, Wang L, Li Q and Yan H: Narcolepsy onset is seasonal and increased following the 2009 HINI pandemic in China. Ann Neurol 70(3): 410-417, 2011. 
18 Sen G: Viruses and interferons. Annu Rev Microbiol 55(1): 255281, 2001.

19 Dummer R, and Mangana J: Long-term pegylated interferonalpha and its potential in the treatment of melanoma. Biologics 3: 169-182, 2009.

20 Rosenberg S, Mulé J, Spiess P, Reichert C and Schwarz S: Regression of established pulmonary metastases and subcutaneous tumor mediated by the systemic administration of high-dose recombinant interleukin 2. J Exp Med 161(5): 1169, 1985.
21 Iwasaki A and Medzhitow R: Toll-like receptor control of the adaptive immune response. Nat Immunol 5(10): 987-95, 2004.

22 Agarwala S: An update on pegylated ifn- $\alpha 2 b$ for the adjuvant treatment of melanoma. Expert Rev. Anticancer Ther 12(11): 1449-1459, 2012.

Received January 13, 2017

Revised February 21, 2017

Accepted February 24, 2017 